\title{
Editorial
}

\section{Volume 35, Number 1 of Culture, Medicine and Psychiatry}

\author{
Brandy L. Schillace • Atwood D. Gaines
}

Published online: 24 December 2010

(C) Springer Science+Business Media, LLC 2010

As we move into the New Year, we find ourselves reflecting upon the development of our Journal's categories, its diversity of submissions, and its changing front cover. The images presented for this, the 35th volume of Culture, Medicine and Psychiatry, pay homage once again to both Eastern and Western medicines. The particular focus is, however, on the clinic - the Mayo Clinic, particularly, but the evolving idea of clinics in general as places of healing. We are grateful to the Mayo clinic for allowing permission to represent the surgeon's club, and we are grateful, too, for our other contributors and their instructive historical images and artifacts. In future, the CMP cover images will rotate per volume, replaying the development and value of both Western and non-Western medical traditions.

In addition to a cover change, we have also added a new Quote of the Volume. Following the quotes by E.E. Evans-Pritchard and Sigmund Freud, this year's quote comes from an established feminist author, Juliet Mitchell, from her Feminism and Psychoanalysis. She is also the author of Mad Men and Medusas, Feminine Sexuality, Women: the Longest Revolution and co-author of British Feminist Thought and the editor of The Selected Melanie Klein.

In terms of editorial staff, we have several staff changes to highlight. Brandy L. Schillace remains the Managing Editor of $C M P$, but she is now an Assistant Professor at Winona State University in Minnesota. Her contact information for the purposes of submissions and journal communications remains the same, but she now shares correspondence responsibility with Stephanie McClure, who is a doctoral candidate in anthropology at Case Western Reserve University. Previously

B. L. Schillace $(\square)$

Winona State University, Winona, MN 55987, USA

e-mail: brandy.schillace@case.edu

\section{A. D. Gaines}

Department of Anthropology, Case Western Reserve University, Cleveland, OH 44106-7125, USA

e-mail: atwood.gaines@case.edu 
the Editorial Associate, Stephanie is now the Assistant Managing Editor. These changes will further strengthen the editorial staff and facilitate efficient response times for our authors. Kristi Ninnemann, MPH is now our Editorial Assistant.

Finally, no new-volume editorial would be complete without a sincere note of thanks to our contributors, reviewers, board members and staff. It is a privilege and an honor to work with all of you, and your time and commitment remains the backbone of Culture, Medicine and Psychiatry. As we write, we look forward to the New Year. 